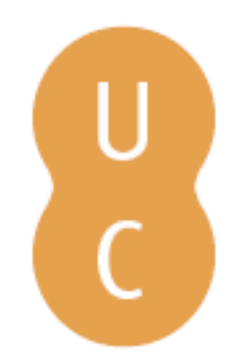

\title{
pompalina
}

\section{O desamor do contraditório: elementos para uma problemática da prova}

\author{
Autor(es): Martins, Rui Cunha \\ Publicado por: Imprensa da Universidade de Coimbra \\ URL \\ persistente: \\ URI:http://hdl.handle.net/10316.2/31572 \\ DOI: \\ DOI:http://dx.doi.org/10.14195/978-989-26-0199-1_3
}

Accessed : $\quad$ 26-Apr-2023 14:19:41

A navegação consulta e descarregamento dos títulos inseridos nas Bibliotecas Digitais UC Digitalis, UC Pombalina e UC Impactum, pressupõem a aceitação plena e sem reservas dos Termos e Condições de Uso destas Bibliotecas Digitais, disponíveis em https://digitalis.uc.pt/pt-pt/termos.

Conforme exposto nos referidos Termos e Condições de Uso, o descarregamento de títulos de acesso restrito requer uma licença válida de autorização devendo o utilizador aceder ao(s) documento(s) a partir de um endereço de IP da instituição detentora da supramencionada licença.

Ao utilizador é apenas permitido o descarregamento para uso pessoal, pelo que o emprego do(s) título(s) descarregado(s) para outro fim, designadamente comercial, carece de autorização do respetivo autor ou editor da obra.

Na medida em que todas as obras da UC Digitalis se encontram protegidas pelo Código do Direito de Autor e Direitos Conexos e demais legislação aplicável, toda a cópia, parcial ou total, deste documento, nos casos em que é legalmente admitida, deverá conter ou fazer-se acompanhar por este aviso.

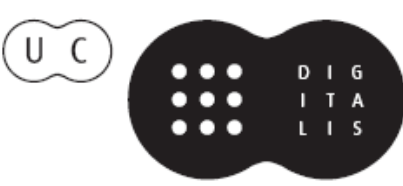


Maria Manuela Tavares Ribeiro

Coordenação

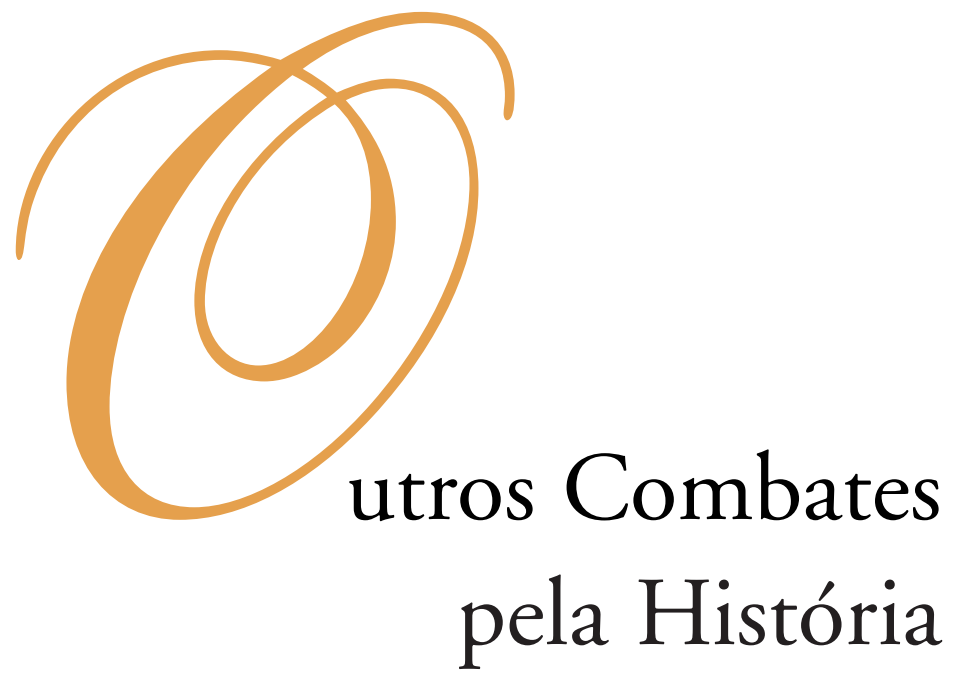




\section{COORDENAÇĀO EDITORIAL}

Imprensa da Universidade de Coimbra

Email: imprensauc@ci.uc.pt

URL: http://www.uc.pt/imprensa_uc

Vendas online: http://livrariadaimprensa.com

\section{CONCEPÇÃO GRÁFICA}

António Barros

\section{ORgANIZAÇĀO DOS TEXTOS}

Isabel Maria Luciano

Marlene Taveira

PRÉ-IMPRESSÃO

António Resende

Imprensa da Universidade de Coimbra

EXECUÇÃO GRÁFICA

SerSilito • Maia

ISBN

978-989-26-0041-3

DEPósito LEGAL

OBRA PUBLICADA COM O APOIO DE:

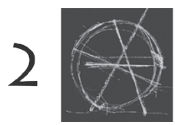

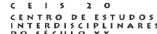

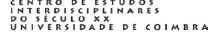

FCT Fundação para a Ciência e a Tecnologia

MINISTÉRIO DA CIÊNCIA, TECNOLOGIA E ENSINO SUPERIOR Portugal

Programa Operacional Ciência, Tecnologia, INOVAÇĀo DO QUADRo COMUNITÁRIO DE APOIO III

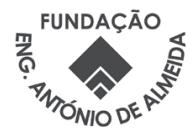

C JULHO 2010, IMPRENSA DA UNIVERSIDADE DE COIMBRA 
Maria Manuela Tavares Ribeiro

Coordenação

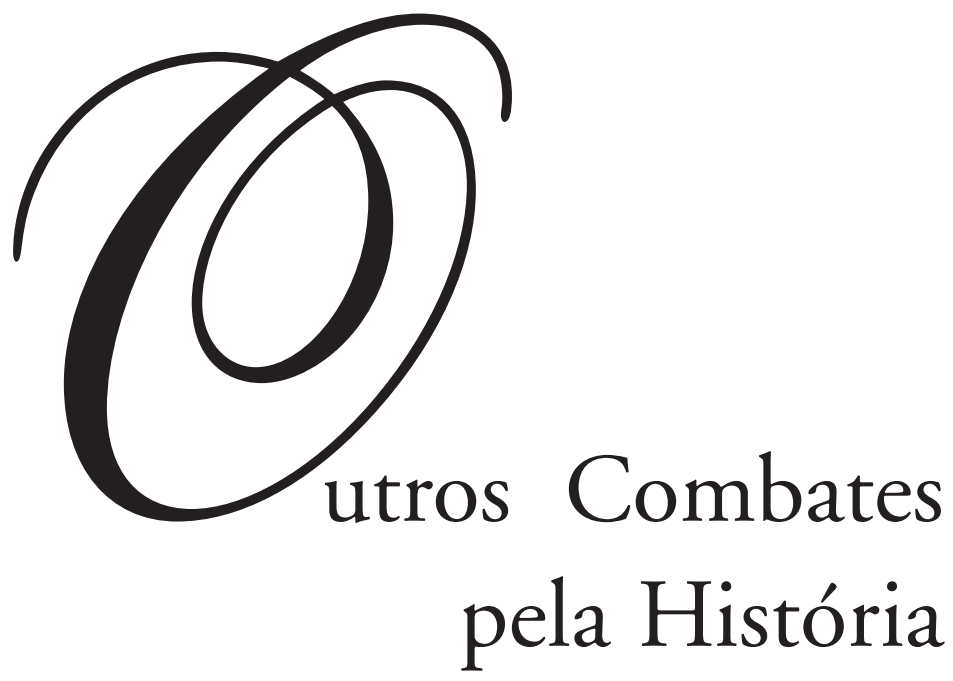

- colmbra 2010 
Outras Teorias da História 


\title{
Rui Cunha Martins
}

\author{
O DESAMOR DO CONTRADITÓRIO. \\ ELEMENTOS PARA UMA PROBLEMÁTICA DA PROVA
}

\section{Pressupostos}

Diz-se evidente o que dispensa a prova. Simulacro de auto-referencialidade, pretensão de uma justificação centrada em si mesmo, a evidência corresponde a uma satisfação demasiado rápida perante indicadores de mera plausibilidade. De alguma maneira, a evidência instaura um desamor do contraditório. Dotada de semelhante quadro de valências, suposto seria que ela visse blindada a sua participação em qualquer dispositivo crítico ou processual destinado a instituir-se em limite contra a arbitrariedade. Mas as coisas não se passam desse modo linear. Desde logo, por via dos elevados índices de porosidade característicos das modalidades de constrangimento à evidência tradicionalmente disponíveis no âmbito dos regimes da prova e da verdade. E, depois, por via da própria capacidade da evidência para se instalar no que seriam, à partida, os seus pólos opostos — é, designadamente, o caso da convicção, nunca suficientemente resguardada da crença que nela está subsumida e que nela é expressão da evidência, e é o caso da prova, cujos momentos de desregulação e cujas expressões de excesso ou ostensividade a inclinam, sem retorno, para o lado da evidência.

Assim posta a questão, há um aspecto fundamental a reter. A premonição contra as insinuações processuais da evidência não se alcança mediante uma mera acentuação do carácter corrector da prova - porque, conforme se assinalou, a prova é sequestrável - mas sim através de uma permanente atenção aos modos da prova, ou, dito de outro modo, ao ambiente de captação e instalação da prova, que é onde verdadeiramente se joga a sua maior ou menor capacidade de filtragem. A prova, por si só, como bandeira de legalidade ou de legitimação de juízo, de pouco serve. Processualmente falando, a prova tem que provar. Outro tanto se poderá dizer em sede de convicção, mecanismo cuja vertente de "zona de contágio» não pode ser subestimada. Destas questôes se ocupará o presente texto. O pressuposto em que ele se funda é o de que, transportando a evidência o que poderemos designar por vertigem anti-crítica e anti-democrática — isto é, para todos os efeitos, anti-mediadora —, parece de todo justificável uma reflexão sobre o lugar explícito ou implícito por ela ocupado no âmbito de palcos políticos e críticos precisamente erigidos sobre fundamentos em tudo 
contrastantes com aquela vertigem e que por vocação a deveriam descartar sem mácula, mas cuja admissão mais ou menos tensa obriga a perguntar, em cada momento, pelo seu efectivo empenho nas operações de constrangimento à evidência. Neste sentido se dirá, por exemplo, que o «Estado Democrático de Direito» será, de facto, tanto mais democrático e de direito, consoante os mecanismos destinados a assegurar os seus princípios basilares (o da legalidade é inegavelmente um deles ${ }^{1}$ ) apresentem, pela sua parte, um grau tão mínimo quanto possível de contaminação pelas expressões da evidência. Como se dirá, na mesma linha, que a "operação historiográfica» será tanto mais eficaz e pertinente consoante saiba expressar "o cariz mediato e mediado" do tipo de conhecimento por ela assegurado ${ }^{2}$, o qual, ao remeter para a impossibilidade de uma fusão acrítica entre o visto e o respectivo sentido (porque a tarefa da selectividade, apanágio da função do historiador, impõe essa distância), constitui reserva de resistência à avidez imediatista da evidência.

\section{O lugar da evidência}

É possível constranger a evidência? Idealmente, sim. Existem, pelo menos, mecanismos expressamente destinados a essa função. Cada um à sua maneira, a prova, a convicção, ou o próprio processo destinam-se a assegurar o estabelecimento de limites frente à pulsão devoradora da evidência. O problema que se coloca é, porém, o da efectividade do respectivo desempenho. Ora, trata-se de uma missão de algum modo condenada ao fracasso - não apenas nenhum daqueles operadores alcança níveis de total satisfação regulatória, como se verifica a sua tendencial "contaminação" pelo registo da evidência.

Em trabalho relativamente recente, tive oportunidade de ensaiar, em conjunto com Fernando Gil, uma problemática para este assunto ${ }^{3}$. Tratou-se de um exercício a todos os títulos estimulante: a Gil se devem obras de referência sobre prova, evidência, convicção, ou crença ${ }^{4}$; e se é verdade que algumas das plataformas críticas atingidas no nosso referido trabalho não me satisfazem hoje inteiramente, o certo é que a sua recuperação permite fixar determinados pontos insubstituíveis para o debate. Vejamos quais.

a. Admitindo-se (conforme autorizam estudos prévios em torno da noção de verdade) a existência simultânea de uma verdade da evidência e de uma verdade da prova, admissível se torna que a verdade da evidência seja alheia à ideia de processo, enquanto que a verdade da prova não o deverá ser. Eis o motivo:

\footnotetext{
1 BRANDĀO, 2002, 65-69.

2 Catroga, 2009, 124.

3 Refiro-me ao diálogo publicado em Gil e MARTins, 2002.

${ }^{4}$ Ao longo deste artigo, as obras de Fernando Gil designar-se-ão pelas respectivas siglas $[\mathrm{A}=$ Acentos; $\mathrm{C}=$ La Conviction $; \mathrm{M}=$ Mediaçóes $; \mathrm{ME}=$ Modos da Evidência $; \mathrm{MV}=$ Modos da verdade $; \mathrm{P}=$ Provas $;$ $\mathrm{PC}=$ Processo da Crença $; \mathrm{TE}=$ Tratado da Evidência $]$, devidamente descodificadas na tabela de correspondência incluída na bibliografia final.
} 
diferentemente da prova, a evidência não remete para dispositivos exteriores de avaliação, porque ela constitui um desdobramento do sentido na indicação da sua própria verdade, pondo-se por si, quer dizer, alucinando. Significa isto o seguinte: que será, desejavelmente, à prova que vai caber trabalhar a verdade de modo não alucinatório; que, assim sendo, a prova deverá desempenhar, de alguma maneira, um efeito de correcção sobre esse carácter alucinatório; e que, sempre em termos ideais, será ainda a prova a retirar a verdade do albergue da evidência, sujeitando-a ao exame do processo.

b. Transpondo para a prova os critérios (de verdade, de justificação e de aceitação) classicamente estimados como condições do saber, dir-se-á que uma proposição P está provada se: (i) P tem um objecto existente (condição de objectividade); (ii) P é esteada por operadores de prova (a demonstração, a experimentação e os outros meios de prova), e (iii) eu assentir a P. Ou seja: uma condição de objectividade, uma condição de esteio, e uma condição de assentimento. Ora, pelo menos esta última condição inscreve-se ainda no registo da evidência, ela é o que na prova resta da evidência e da crença: o assentimento é da ordem da adesão, aqui adesão à prova tal como ela se efectuou (na realidade, crença e evidência intervêm também nas outras condições).

c. Supostamente, a condição de assentimento acha-se limitada pelas outras — nas quais, pelo menos em princípio, não há lugar para a evidência nem para a crença. Tanto assim é que, se os procedimentos da prova que asseguram $i$ e $i i$ não são respeitados, está-se perante uma "patologia da prova", cuja figura mais geral é precisamente a instalação directa do sujeito no assentimento, sem obedecer às condiçôes de objectividade e de esteio. Contudo, mesmo admitindo que boa parte do trajecto histórico do direito dá conta de preocupaçōes destinadas a garantir o esteio e a justificação, o certo é que a evidência nunca desapareceu completamente do campo do direito, como ressalta, por exemplo, da importância que o testemunho conserva enquanto elemento de prova (norteia o testemunho a ideia de que ele substitui, ou dá a conhecer, sem a adulterar, a experiência directa dos factos, como se fossem estes a relatar-se a si mesmos, prescindindo de esforços exteriores de mediação), ou do papel da convicção do juiz, directamente relacionada com o assentimento (afinal, é o juiz que aceita ou não, com significativa liberdade, os modos de esteio e de objectividade que lhe são propostos) $)^{5}$.

Todos estes aspectos nos permitem entender melhor os termos em que se formula o paradoxo da prova. «A prova não deve ser fraca: prova fraca é aquela que se satisfaz com a verosimilhança, com o que se diz ser uma crença racional. Mas a verosimilhança que, fora da lógica e da matemática, é o regime normal da prova, não é em si um critério satisfatório, por mais convincente que seja. A verosimilhança não remove a

${ }^{5}$ Estas três alíneas recolhem, com alteraçōes, excertos do diálogo publicado em MV, em especial nas páginas 21-27. 
eventualidade de excepções e de contra-exemplos — e as crenças racionais podem revelar-se erróneas: os erros judiciários assentam sempre em verosimilhanças e crenças racionais. Portanto, a prova tem de ser forte. Mas a prova forte revela-se de imediato demasiado forte» ${ }^{6}$ - e, nesse momento, se essa demasia se dá nos termos de uma ostensão de feição patológica, ela resvala sem escape para o terreno da evidência, a qual, veja-se a ironia, tende a dispensar a prova. Paradoxo inescapável, ainda assim. É que a vertigem alucinatória da prova não decorre de uma momentânea apetência desviante, prendendo-se antes com uma das suas vertentes constitutivas mais nucleares, ainda que das menos ditas. Chamar-lhe-ei a percepção do destinatário. Porque provar é em boa medida convencer.

\section{A questão do destinatário}

«Não há saber nem prova sem destinatário». Aqui, Fernando Gil decalca de modo propositado Wittgenstein, para quem o essencial da prova é engendrar a "convicção". De notar que, nesta perspectiva, essa convicção não constitui uma simples resposta, quase reflexa, à demonstração que a engendra. A demonstração que serve de suporte e que constrói a prova visa obter algo mais do que uma aceitação relativa aos procedimentos formais, ela visa, precisamente, suscitar a convicção. Daí a ideia com que se fica de que, nesta linha de raciocínio, uma prova que não provocasse uma convicção não seria uma prova ${ }^{7}$.

Igualmente instrutiva se revela a convocatória de Leibniz para o debate. Gil não deixa de assinalar a fecundidade da reflexão leibniziana sobre o cruzamento entre epistemologia e direito (uma reflexão estribada, no essencial, sobre o processo judicial), investimento analítico que lhe permite equacionar o problema nuclear do destinatário: «a prova é indissociável de um assentimento que apresenta graus e o problema que coloca é, pois, o seguinte: em que condiçōes e segundo que critérios um juízo ou uma teoria devem ser declarados suficientemente justificados, de modo a suscitarem convicção?» 8 .

Não será despiciendo lembrar que a convicção, genericamente considerada, e, por maioria de razão, esta convicção que assim se vê colocada na posição de receptora do investimento probatório, corresponde, por definição, a uma crença corrigida. $\mathrm{Na}$ crença, justamente, a marca da evidência impor-se-ia de um modo que não ocorreria já na convicção. Mas isso pode não significar mais do que uma diferença de grau, a persistência da marca da evidência no campo da convicção é frequente. Sucede, com efeito, que a contaminação da convicção pela crença é um dado tão constitutivo da primeira como da segunda. "A convicção é da ordem da verdade. A crença é a sede da ideologia. Mas interpenetram-se» ${ }^{9}$. E, ao que tudo indica, o mecanismo epistémico que assegura essa interpenetração, mediando o jogo de sobreposições, é, fundamentalmente,

\footnotetext{
${ }^{6} \mathrm{ME}, 91$.

7 A, 27-28.

8 P, 24.

${ }^{9} \mathrm{C}, 95$.
} 
a adesão. É através dela que o assentimento, condição da convicção, se constitui em expressão máxima do contágio da convicção pela crença e, nesse sentido, em expressão de uma brecha mais nos modelos de constrangimento à evidência. "A adesão é o sinete e o conteúdo afectivo da crença: não há crença sem adesão — tal como se adere apenas àquilo em que se crê: não há adesão sem crença» ${ }^{10}$.

Por outro lado, é de novo a leitura de Wittgenstein a permitir notar que «não há convicção definitivamente premunida contra o excesso de certeza». Naturalmente: «no que tem de mais próprio, a convicção é uma forma particular de certeza emergente da actividade cognitiva, à qual retorna. Ela funciona, então, como um princípio que não requer já ser verificado em cada utilização». Assim se explica que «se a prova se desdobra em certeza, em contrapartida, a convicção nem sempre requer prova» e, mais ainda, que "as convicções mais certas não são susceptíveis de demonstração" ${ }^{11}$. Bem se compreende pelo exposto que, como assinala Gil, a convicção wittgensteiniana não é uma certeza de segunda ordem mas age como uma disposição radicada no espírito $^{12}$. Haverá, nesta óptica, como que uma disposição impensada para o exercício da convicção. A mesma disposição, aliás, que permite estabelecer um nexo forte entre convicção e confiança, visto que, naquela mesma ordem de ideias, também confiar "é muito simplesmente a condição nativa do espírito" ${ }^{13}$. Trata-se de um nexo importante. Tenha-se em conta que a noção de confiança é inextricável da noção de adesão. O círculo da evidência aperta-se.

E, de facto, veja-se o nó epistemológico que neste exacto ponto se instala. Se parece aceitável a ideia de que "há graus de adesão [incluindo] os casos em que ela é máxima», forçoso será recordar que, neste último caso, o do grau máximo de adesão, «a crença chamar-se-á então confiança». Ora, a confiança, "que é talvez a matriz da crença em geral» («a mente é naturalmente confiante»), «repousa sobre um pressuposto de identidade e estabilidade» ${ }^{14}$. O que nos leva, sem alternativa, à ideia de «normalidade», base epistémica da presunção. De modo suave, mas irreversível, afastamo-nos do constrangimento e da prova. A presunção é apanágio da evidência.

Presume-se em função de referentes de normalidade e de estabilidade. Presumir é proceder, quase inconscientemente, a uma mobilização, entretanto naturalizada, de uma lógica estatística, no âmbito da qual os elementos de repetição e os valores de homogeneidade e coerência a eles associados configuram uma estética do preferível, esse correspondente moral do plausível. A verdadeira dimensão deste ponto percebe-se melhor quando colocada no contexto concreto do mundo jurídico: "Ao tipo de prova que se pesquisa corresponde um prognóstico, mais ou menos seguro, da real existência do thema probandum e, sem dúvida, também das consequências jurídicas que podem advir da positivação da questão fáctica». Eis por que razão «a ordem das coisas colocadas no processo permite, pragmaticamente, constatarmos que a acção voltada à introdução do material probatório é precedida da consideração psicológica

\footnotetext{
$10 \mathrm{C}, 91$.

${ }^{11} \mathrm{C}, 95,191-192$.

12 C, 192.

13 C, 191.

14 PC, 434.
} 
pertinente aos rumos que o citado material, se efectivamente incorporado ao feito, possa determinar». Em suma, "quem procura sabe ao certo o que pretende encontrar e isso, em termos de processo penal condenatório, representa uma inclinação ou tendência perigosamente comprometedora da imparcialidade do julgador» ${ }^{15}$. Até porque, nesta perspectiva, a presunção mobiliza, sem o assumir, um ponto de vista e uma carga ideológica que são precisamente o que ela tem por adquirido não dever desvelar ou sequer admitir a respectiva presença ${ }^{16}$.

Reparar-se-á que se joga aqui um problema fulcral de qualquer tipo de regime processual: a gestão das expectativas. A expectativa funde presunção e normalidade. Se a presunção «faz-se acompanhar de uma pré-ocupação do terreno» (podendo, por isso mesmo, «introduzir entorses no regime da prova») ${ }^{17}$, a expectativa antecipa um preenchimento (toda a expectativa visa ser preenchida), que, até indicação em contrário, será sempre o preenchimento projectado a partir do que se presume expectável, quer dizer, a partir do que convém à noção de normalidade. Uma vez mais, e cada vez mais, eis-nos confrontados com o vicioso eterno retorno ao reino da evidência.

\section{A gestão das expectativas}

Assinala Gil o modo nítido como o pensamento wittgensteiniano associa regularidades e expectativas: "A nossa expectativa antecipa o acontecimento. Neste sentido, ela faz um modelo do acontecimento» ${ }^{18}$. São assinaláveis, de resto, os sucessivos desdobramentos desta ideia que se recolhem da obra wittgensteiniana, a exemplo daquele que sustenta que «uma expectativa está encastoada (eingebettet) na situação de que brota (entspringt) [e que] o mesmo se pode dizer da intenção (Absicht), [a qual também] está encastoada na situação, nos costumes e nas instituições humanas» ${ }^{19}$.

Gil retira desta leitura as devidas consequências: «faz parte das condições do exercício da linguagem, da sua gramática, uma crença fundada na estabilidade de um grande número de fenómenos e de comportamentos, ou, por outras palavras, uma presunção de uniformidade; toda a expectativa assenta nesta hipótese de constância» ${ }^{20}$. Não admira, pois, a relação de proximidade entre o estado de expectativa e o estado de ajustamento ou conveniência. A complementaridade entre ambos é patente. Quer isto dizer, para os propósitos da nossa reflexão, que é o ajustamento à normalidade que, em rigor, solicita o preenchimento. A projecção de um conhecimento prévio naquilo que há-de vir, modelo por excelência da parelha expectativa/preenchimento, embraia na experiência. Por isso se torna possível afirmar, no seguimento da passagem atrás citada, que «a expectativa reporta-se sem intermediário à realidade» 21 .

\footnotetext{
15 PRADO, 2001, 158.

16 Miranda COUTINHO, 2001, 47-48.

$17 \mathrm{M}, 78$.

${ }^{18} \mathrm{ME}, 67$.

19 Idem.

${ }^{20} \mathrm{ME}, 67$.

$21 \mathrm{ME}, 70$.
} 
Sem intermediário, note-se. De forma directa, por conseguinte, alheia a avaliações extrínsecas ou a mediações. Não merece, pois, reserva de monta, a constatação de que a expectativa funciona no registo da evidência. Tenha-se em atenção que «a linguagem da evidência procura anular as mediações, a distância, a obscuridade, o silêncio, o arbitrário individual» 22 . Anotação abonatória de que "o par expectativa/preenchimento pertence à arqueologia da evidência, [correspondendo a] uma estrutura «arcaica» da compreensão» ${ }^{23}$. De resto, "desejar, esperar, ter intenção de, crer, querer, poder alguma coisa, mandar — de certa forma todos estes verbos intencionais se acompanham por expectativas. Elas não são da mesma natureza em todos os casos, podem situar-se mais perto do possível ou da efectividade, a exigência do preenchimento será mais ou menos imediata: mas uma ordem espera a sua execução, como um voto ou uma esperança esperam a sua satisfação, uma decisão ou um plano a sua realização, uma intenção a sua efectivação, uma conjectura a sua confirmação» 24 .

Bem se pode dizer, nesta linha, que, sempre que o acontecimento previsto é constatado, estávamos de alguma forma "preparados» para a constatação ${ }^{25}$. É isto, verdadeiramente, o sentimento de preenchimento. Ele corresponde à satisfação de algo que começa por se apresentar como um desejo e que, de uma maneira ou de outra, deve ser cumprido. Aflora, neste ponto, uma interrogação inquietante: qual a disponibilidade da expectativa para ver frustrado esse sentimento e para ser invadida pelo sentimento de insatisfação? Pouca, ao que parece. Deve, inclusive, supor-se que o horror da expectativa ao vazio, ao silêncio e à demora traduz essa menor disponibilidade. A conivência da expectativa com a evidência radica aqui, nesta preferência pelo imediato. Um imediato que tem no argumento da "celeridade» (tome-se por exemplar o uso que é feito desta noção no campo jurídico, mormente em ordem à justificação de restrições em matéria de garantia processual) uma expressão tópica. Trata-se, nestes casos, de comprimir a distância entre o expectável e o realizável, deslocando, se necessário for, o campo da experiência e a regularidade do que se repete — feitas normalidade - para o lugar do preenchimento, e prescindindo, nesse movimento de fusão entre o que se sabe e o que se espera, de mecanismos de despistagem ou de operadores de constrangimento sobre a «irrecusável» evidência daquilo que, porque é repetidamente sabido, se supõe ser aceite, sem mais, como previsível. O circuito vertiginoso dos meios de comunicação é de igual modo um bom exemplo destes processos. Não deixa de ser curioso notar que, muito antes deles, o «direito arcaico» também o era.

Com efeito, no âmbito desse direito colado ao ritual que é o «direito arcaico» e em que «a administração da prova se dirige, não a um juiz que deve apreciar, mas a um adversário que é preciso "vencer", convencendo-o, [...] as fórmulas dizem-se, as suas contrapartidas materiais e as vindictas impóem-se, o direito exerce-se imediatamente. O processo cria o direito no acto do seu próprio presente [e] a verdade [neste direito arcaico] é nele a irradiação de uma evidência; um acto ritualizado prova ipso facto o

\footnotetext{
$22 \mathrm{TE}, 72$

$23 \mathrm{ME}, 65$.

${ }^{24} \mathrm{ME}, 73$.

$25 \mathrm{ME}, 74$.
} 
direito que ao mesmo tempo produz» ${ }^{26}$. Além disso, e porque o modelo primordial deste direito, a flagrância, suscita uma execução imediata, transparece deste procedimento «um certo ideal do direito criminal: que a sanção forme um só corpo, sem interstício, com o facto delituoso, [num quadro sancionatório] que exclui a administração da prova» ${ }^{27}$. Já o havíamos realçado: a linguagem da evidência encurta distâncias; quando radicalizada, prescinde mesmo da mediação. A vontade de preenchimento é nela mais forte do que qualquer tipo de predisposição auto-regulatória. Por isso, carente de filtragem crítica ou da hipótese de contradição, tende a exprimir-se no modo alucinatório.

Que quer isto dizer? À vista desarmada, que a evidência se caracteriza pelo seu excesso. Mas, dito isto, importa esclarecer que este mesmo excesso decorre, fundamentalmente, de uma intensificação, ou de um transporte, e não tanto de uma pura e directa reificação alternativa do significado. Até porque, bem vistas as coisas, o que está em causa no funcionamento da evidência é mesmo a possibilidade de o signo participar da natureza do significado, do mesmo modo que o ícone partilha aí as propriedades do representado. Correcto será, então, referir que «a evidência representa uma alucinação, mas não no sentido de um percepto do irreal em vez da percepção do existente: antes significa a transposição $d a$ percepção para outra coisa que não ela mesma. É uma operação alucinatória que, com a força irrecusável do real, converte em verdade a percepção e a significação» 28 .

Se, por conseguinte, de acordo com o que tem apontado a nossa linha reflexiva, todo o dispositivo processual apresenta modalidades variadas de contaminação pela evidência, e se, conforme acabamos de ver, essa evidência tende a alucinar como produtora de verdade - isto é, para todos os efeitos, como participante dos mecanismos de verdade que supostamente lhe deveriam estar vedados —, pergunta-se: que fazer com essa mesma verdade, assim paradoxalmente contaminada? Nestes ou noutros moldes, a pergunta tem sido formulada com gradual insistência ${ }^{29}$. As respostas diferem.

\section{A de-composição do verdadeiro}

Quanto à verdade e ao seu lugar (a verdade é sempre uma questão de lugar), a posição talvez mais séria, pelo menos a mais fecunda, é a que vai para lá do clássico paradigma da verdade como adequação, resistindo, porém, a fazer dessa ultrapassagem uma porta aberta ao que chamarei o paradigma da verdade exilada, isto é, uma verdade expulsa do sistema.

Este aspecto é importante. Traz subjacente a ideia de uma condição processual do verdadeiro. Remete-se, com esta expressão, para o carácter sistémico que há-de convir a todos os elementos participantes de qualquer dispositivo processual (e a verdade é, muito simplesmente, um deles), em relação aos quais pode dizer-se serem sistemicamente

\footnotetext{
$26 \mathrm{TE}, 36$.

$27 \mathrm{TE}, 40$.

$28 \mathrm{TE}, 217$.

29 Por exemplo LOPES JR.., 2007, 536-549.
} 
produzidos. Não lidamos, pois, com componentes isolados, tão dispersos quanto hierarquizados — imagem de resto destituída de ancoragem funcional — mas antes com um dispositivo complexo, configurador de geometrias variáveis a partir da articulação dos seus vários elementos constitutivos. Um dispositivo onde, fatalmente, a verdade emerge do «imbricamento do manancial de significantes» 30 , fatalidade que, por vocação, os sistemas processuais vulneráveis à sedução da evidência se afadigam a escamotear.

Percebe-se que semelhante leitura afunde, sem solução, o cânone da verdade como rainha do processo (por norma concretizado através da figura da verdade como adequação), desde logo porque, no âmbito de um entendimento configuracional ou sistémico dos sistemas processuais, é a própria ideia de topo hierárquico previamente atribuído a um dos componentes que não se sustenta. Mas, uma vez reconhecido este aspecto, de modo idêntico se perceberá a impossibilidade de, a partir da referida leitura, dar por exaurido, sem mais, o próprio lugar da verdade, ainda que em nome da necessidade de eliminar o mais possível do quadro processual os marcadores da evidência. Pense-se: como extirpar de um dispositivo, organicamente expresso em moldes sistémicos, um elemento que retira a sua condição funcional da interacção com os restantes e que, assim sendo, não ocupa, em concreto, um lugar preciso? Como fazê-lo em relação a um componente que é continuamente produzido por, tanto quanto produz, os sistemas intersubjectivos que fundam o dispositivo?

Encarada como elemento inserido, por definição, no denso cruzamento de mecanismos, operadores, propriedades, contágios e subsistemas em presença, a verdade pouca eficácia retirará de uma aposta preferencial na sua versão de "verdade-adequação». Já, pelo contrário, na sua versão de verdade-afinidade (sumariamente definida como uma verdade produzida em contexto de «entreexpressão», a partir da articulação entre componentes tão distintos quanto complementares — afins, portanto — residentes em um mesmo ambiente sistémico) ${ }^{31}$, o seu desempenho afigura-se exequível.

A pedra de toque da questão passa, deste ponto de vista, pela forma como se traduz, na prática, a ideia atrás aduzida de uma condição processual do verdadeiro. E esta só pode querer dizer que a verdade corresponde ao somatório de vários momentos, de vários cruzamentos funcionais e de várias plataformas intra-sistémicas, sendo justamente esses momentos, esses cruzamentos e essas plataformas, ou seja, esse processo articulado de interacção entre a verdade e os mecanismos que lhe são afins, aquilo que demarca o tipo de verdade em exercício e, por isso mesmo, aquilo que importa ter a possibilidade de decompor. Nesta perspectiva, o verdadeiro será aquilo que eu posso de-compor, aquilo que me permite reconhecer o carácter processualmente construído que lhe subjaz.

Sempre que essa operação me estiver vedada, não estou já ao nível da verdade, independentemente do grau de contaminação que esta apresente; estou, declaradamente, ao nível da evidência, à qual não convém a complexidade da decomposição. Entretanto, a possibilidade de, ao invés, a decomposição me ser permitida significa, com muita probabilidade, que a verdade em causa aceita denunciar as condições processuais da sua instrução, que ela se oferece enquanto intersubjectividade e que, tido em conta que «o paradigma do Estado Democrático de Direito está assente na

30 MORAIS DA ROSA, 2006, 366.

31 TUNHAS, 2008, 61. 
intersubjectividade» ${ }^{32}$, esse modo da verdade é em algum ponto compaginável com esse mesmo Estado de Direito. Será pouco? De modo algum: significa que a operatividade dessa verdade se faz depender da respectiva capacidade para exprimir os valores democráticos e constitucionais. E, como no fundo todos sabemos, não há melhor operador de constrangimento sobre a evidência do que uma Constituição.

Os valores constitucionais são compatíveis com o Estado de Direito; os regimes da evidência são com ele incompatíveis. Entre ambos, não parece que ao sistema processual possa caber grande margem de escolha. A sua inclinação fornece, em qualquer dos casos, um sinal político — na certeza de que não há aprofundamento democrático que possa prescindir de umas quantas incompatibilidades electivas.

\section{REFERÊNCIAS}

\section{Obras de Fernando Gil citadas no texto (siglas e títulos correspondentes):}

[A] GIL, Fernando, Acentos. Lisboa: Imprensa Nacional-Casa da Moeda, 2005.

[C] GIL, Fernando, La conviction. Paris: Flammarion, 2000.

[M] GiL, Fernando, Mediações. Lisboa: Imprensa Nacional-Casa da Moeda, 2001.

[ME] GIL, Fernando, Modos da Evidência. Lisboa: Imprensa Nacional-Casa da Moeda, 1998.

[MV] GIL, Fernando; MarTins, Rui Cunha, «Modos da verdade», Revista de História das Ideias, n. 23 (ano 2002), pp. 15-39.

[P] GIL, Fernando, Provas. Lisboa: Imprensa Nacional-Casa da Moeda, 1986.

[PC] Gil, Fernando; Livet, Pierre; CABral, João Pina (orgs), O Processo da Crença. Lisboa: Gradiva, 2004.

[TE] GIL, Fernando, Tratado da Evidência. Lisboa: Imprensa Nacional-Casa da Moeda, 1996.

\section{Outras referências bibliográficas:}

Brandão, Cláudio, Introdução ao Direito Penal. Análise do sistema penal à luz do Princípio da Legalidade. Rio de Janeiro: Editora Forense, 2002.

Catroga, Fernando, Os Passos do Homem como Restolho do Tempo. Memória e Fim do Fim da História. Coimbra: Almedina, 2009.

Lopes JR., Aury, Direito Processual e sua Conformidade Constitucional, volume I. Rio de Janeiro: Lumen Juris, 2007.

Martins, Rui Cunha, O ponto cego do Direito. Rio de Janeiro: Lumen Juris [no prelo].

Miranda Coutinho, Jacinto Nelson de (org), Crítica à Teoria Geral do Direito Processual Penal. Rio de Janeiro: Renovar, 2001.

Morais DA RosA, Alexandre, Decisão Penal: Bricolage de Significantes. Rio de Janeiro: Lumen Juris, 2006.

Prado, Geraldo, Sistema Acusatório. A Conformidade Constitucional das Leis Processuais Penais. Rio de Janeiro: Lumen Juris, 2001.

Streck, Lenio Luís, Verdade e Consenso. Constituição, Hermenêutica e Teorias Discursivas. Rio de Janeiro: Lumen Juris, 2006.

Tunhas, Paulo, "Verdade e Imaginação em Mimésis e Negação», in A Razão Apaixonada. Homenagem a Fernando Gil. Lisboa: Imprensa Nacional-Casa da Moeda, 2008.

32 STRECK, 2006, 165. 

Série

Documentos

Imprensa da Universidade de Coimbra

Coimbra University Press

2010

- U

C • 